\title{
Learner Autonomy: Concept and Considerations
}

Madhu Neupane

\begin{abstract}
"Give me a fish and I eat for a day. Teach me to fish and I eat for a lifetime."This proverb taken from Chinese culture is associated with learner autonomy. Once learning used to be the matter of receiving the body of knowledge which could then be used for the rest of life. But such view has been nonsense in this fast-paced world. Therefore, the learners should be provided with the skills necessary for the lifelong pursuit for knowledge. This article begins with the general concept of autonomy and goes on to consider different aspects of autonomy. It insists that learner autonomy does work in any culture provided that the teacher also has autonomy to some extent and curriculum is designed accordingly. While it highlights that total autonomy is neither feasible nor desirable in formal language learning contexts, it argues that learner autonomy is necessary for making someone lifelong learner.
\end{abstract}

Key words: learner autonomy, teacher autonomy, curriculum, culture, activities

\section{Introduction: Defining autonomy}

Autonomy, a relatively new concept in the field of education, has been defined differently by different scholars. Holec (1981 as cited in Schmenk, 2006) was the first person to define the learner autonomy as "the ability to take charge of one's own learning" (p. 3). According to him, this ability is acquired rather than inborn. Taking charge means being able to make regarding all the aspects of language learning. As this suggests this is the total shift of responsibility of learning language to learners. Little (1995) observes that learners autonomy "aims to equip learners to play an active role in participatory democracy" (p. 176). Benson (2008) agrees with Little when he says, "because the concept of autonomy in learning draws its meaning from the concept of personal autonomy, it is centrally concerned with the kind of learning that best helps people to lead autonomous lives" ( $p$. 4). Autonomous life refers to individual freedom with the "free choice of goals and relations as essential ingredients of individual well being" (Raz, 1986, as cited in Benson 2008). In this sense, autonomy has to do with individual freedom and human rights for making individual choices (p. 5). It is a matter of lifelong process rather than a need for a particular situation or course.

As discussed earlier, autonomy for learning is the part of the personal autonomy and we must learn to be autonomous. Education should enable an individual to lead an autonomous life. An autonomous person leads an independent life being responsible for his or her own actions rather than blaming others. So the boarder aim of education can only be fulfilled if learners are provided with the autonomy in learning. An autonomous learner "has the means to transcend the barriers between learning and living that have been a major preoccupation of educational psychology, educational theory and curriculum development" (Little, 1995, p. 175). The main aim of education is to bring change in the behaviour of a person. Behaviour can only be changed when the barriers between the learning and living are transcended. Receiving knowledge without applying it in real life is meaningless. Gardener (1993, as cited in Little 1995) has made distinction between three types of learners "the intuitive learner, the traditional student and the disciplinary expert" (p. 175). The disciplinary expert, according to Gardner, "is an individual of any age who has mastered the concept and skills of a discipline or domain and 
can apply such knowledge appropriately in new situations" (ibid). The autonomous learners are the Gardner's disciplinary expert.

For Schmenk (2006), defining autonomy as it is done in the preceding paragraphs is based on the linear concept of autonomisation which assumes the progression from heteronomy to autonomy.

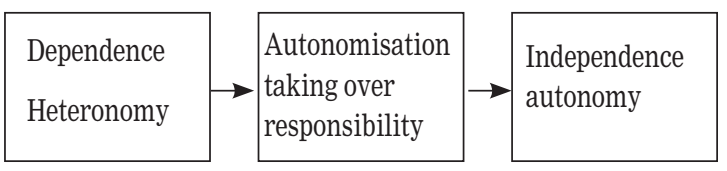

Figure 1: Progression from heteronomy to autonomy (Schmenk 2006, p. 4)

Schmenk, however, insists that "there is dialectic relationship between heteronomy and autonomy. Wherever and whenever there is autonomy, there is also heteronomy (dependence). The notion of progression may gloss over this dialectics, yet it is impossible to simply overcome heteronomous conditions and to reach a state of pure personal autonomy" (p. 81). She makes it clear by quoting Kant and interpreting his idea:

Kant recognized the limits of personal autonomy very clearly when he declared it imperative for autonomous persons to take over responsibility for the autonomy of others [...] subjects are positioned and position themselves within the dialectics of autonomy and heteronomy [...] not only do learners have to accept the broader range of imposed presupposition, regardless of whether or not there is a teacher or an institution involved in their learning. (ibid)

At this point I think it would be relevant to quote Littlewood (2002), who has made a distinction between proactive and reactive autonomy:

The key words of proactive autonomy, B.S. are action words: learners are able to take charge of their own learning, determine their objectives, and select methods and techniques [...]. In this way they establish a personal agenda for their learning which affirms their individuality and sets up directions in a world in which they themselves have partially created [...]. However, in taking about education, it is useful to consider also a second kind of autonomy which may be either a preliminary step towards proactive autonomy or a goal in its own right. This is the kind of autonomy which does not create its own directions, but once the direction has been initiated( for example, by the teacher or the curriculum), enables learners to recognize their resources autonomously in order to reach their goals. (p. 30)

In this distinction proactive autonomy is considered to be pure autonomy where the learners are totally free to make individual choices. Schmenk opines that ...proactive autonomy (total independence) is impossible to achieve. What can be achieved is reactive autonomy (ibid). From the above discussion we can see that autonomy is a part of the broader aim of education. However, there is unlikely to be total autonomy for learners, for formal learning contexts are never free from constraints. Freedom must be exercised within certain necessary constraints. Learner autonomy is, therefore, better understood as reactive autonomy where learners can work on their own within given direction.

\section{Autonomy and culture}

Education and culture are closely related. Culture can be viewed in different levels but whatever the nature of culture it affects education. In the eighteenth century culture was considered to be a universal phenomenon. The same yardstick was used to measure the culture but now the culture is supposed to be a plural concept. Everybody has $a$ culture rather than the culture. This is the concept of cultural relativism. The same thing can be applied to education as well. The techniques and methods applicable in one culture may not be applicable in another culture, and therefore learner autonomy is culture-sensitive. In this regard, Holliday (2007) says, "The issue of autonomy has often been connected with the individualism and collectivism dimension in cultural difference" ( $p$. 20). Individualism in this case has been associated with the culture where people are self-oriented. Self -oriented people give priority to their own feelings and desires. They value autonomous choices and tend to make new relations. On the contrary, the people from collectivist culture are group-oriented. They give priority to groups 
(family, society, community, etc.). In such culture people giving priority to themselves are regarded to be selfish rather than self-dependent. Since they are group-oriented they want few choices. Their identity is based on the groups they belong to. So, according to Holliday, learner autonomy works in individualistic culture rather than in collectivist culture.

However, Ho and Crookall (1995) have a different perspective. Like Holliday they do believe that "while personal autonomy appears to be a universally desirable and beneficial objective, it is important to remember that learner autonomy is exercised within the contexts of specific cultures" (p. 253). They give an example from Chinese community (collectivist) where 'relational hierarchy' and 'social relations' are valued. Because of this culture Chinese students respect authority and take their teacher as authority figure. Ho and Crookall further say that "being autonomous often requires that students work independently of the teacher and this may entail shared decision making as well as presenting options that differ from those of teachers. It is, thus, easy to see why Chinese students would not find autonomy very comfortable, emotionally or indeed intellectually" (p. 237). They, however, say that learner autonomy does work in Chinese culture provided that the activities are designed in such a way that they do appeal the learners. They give example of a simulation activity which, in their research, promoted autonomy because of its unpredictability, and problem sharing nature. According to them Chinese culture is supportive, to some extent to autonomy because of its achievement orientation, and inside outside relationship (group identity).

Smith's (2008) also helps us to underscore the idea that learner autonomy is applicable in any culture:

There persists a tension between pedagogical approaches which construe autonomy primarily as something learners lack and so need to be trained towards and those which take at a starting point the idea that learners of whatever background culture are already able to at least to some degree, to exercise control over their own learning. Supportive engagement of learners existing autonomy can be seen as an important basis for its progressive development; indeed the notion that the learners have the power and right to learn for themselves is seen by many proponents as a fundamental tenet. (p. 396)

This shows that learner autonomy can be applied to any culture irrespective of individualismcollectivism dimensions. People of whatever cultures like individual freedom. It is just a matter of degree. In this respect it is relevant to quote Little (1995) "there is nothing new about learner autonomy; that genuinely successful learners have always been autonomous" (p. 179). Culture, therefore, does not appear to be a barrier for promoting learner autonomy.

\section{Teacher autonomy}

When we talk about a learner, a teacher almost automatically comes there. Then while talking about learner autonomy, there arises a question: Should a teacher be also autonomous to promote learner autonomy? Some scholars do believe that teacher autonomy and learner autonomy should go side by side. If the teacher is not in the position to make independent pedagogical choices, how can he or she enable the learners to do so? Emphasizing the role of teacher autonomy along with learner autonomy, Vieira (2001) writes:

The notion of autonomy should refer both to the learner and the teacher, not just to the learner as is often the case. We have perhaps spent too much time thinking about learners and learning processes, and too little time thinking about teachers and teaching processes. Moreover, in the history of the autonomy field, teachers have systematically been kept backstage, that is, they have not taken a central role in research and pedagogical developments. No wonder then that their interests have been overlooked. (p. 20)

This truly reflects the scenario that learner autonomy without teacher autonomy leads us to nowhere, for teaching process and learning process go side by side. Vieira doubts that "our efforts to promote pedagogy for autonomy in school will have any sustainable effects unless we put teachers centre-stage" (ibid). Her reason for putting the teacher in the centre stage is that "unless teachers 
are free to make pedagogical choices that favor learner autonomy, there is no way that pedagogy for autonomy can flourish in school." She has forwarded four major assumptions for the need of teacher autonomy:

1. Pedagogy for autonomy is an ideological choice and a re(ide)alistic activity;

2. Teacher and learner autonomy are interconnected;

3. Teachers are constrained agents of change;

4. Teacher development needs to be selfdirected, inquiry-oriented, experience-based, collaborative, and locally relevant. (p. 24)

Little (1995) agrees with Vieira since he believes that "teacher autonomy to be prerequisite to learner autonomy" (p. 78). Stevens (2007) also highlights the importance of teacher autonomy by saying, "the teacher who explore and exploit the many opportunities for interaction with peers in online environment are much more likely to adapt the techniques they themselves use for professional development in their classes and thereby MODEL these practices for students" ( $p$. 28). He further says that "teachers who practice autonomy in their own professional development [...] increase the likelihood of producing potentially autonomous and lifelong learners" (ibid). The most important thing, however, is that a teacher lacking the experience of autonomy can talk about the autonomy but is unlikely to promote learner autonomy. Richards and Rodgers (2002) highlight the importance firsthand experience when they quote Clark and Peterson (1986):

The most resilient or core teachers' beliefs are formed on the basis of teachers' own schooling as young students while observing teachers who taught them. Subsequent teacher education appears not to disturb these early beliefs, not least, perhaps, because it rarely addresses them. (p. 252)

The above discussion sheds light on the fact that teachers should be provided with the opportunity to experience autonomy while undergoing through teacher education or training if we want them to promote learner autonomy. At the same time they should also be provided with the opportunity to make pedagogical choices that fit their learners though the total autonomy is not to be expected.
From the above discussion we can conclude that learner autonomy and teacher autonomy are closely related. The dream of learner autonomy is unlikely to come true in the absence of teacher autonomy.

\section{Learner autonomy and responsibility of the teacher}

Learner autonomy is generally defined as the ability of the learners to take charge of their own learning. If so, what is the role of the teacher then? Can learners take charge of their own learning even without the teacher? Is the teacher totally free from the responsibility? Such questions need to be answered. In this regard Little ( n.d.) puts forward three basic pedagogical principles: learner involvement, learner reflection, and appropriate target language use for the development of learner autonomy (p. 3). He has identified the roles and responsibilities of the teacher in such a situation. According to him the teacher should:

- use the target language as the preferred medium of the classroom communication and require the same of her learners;

- involve her learners in a nonstop quest for good learning activities, which are shared, discussed analyzed and evaluated with the whole class- in the target language, to begin with very simple terms;

- help the learners to set their own learning targets and choose their own learning activities subjecting them to discussion, analysis and evaluation- again in the target language;

- require her learners to identify individual learning goals but pursue them through collaborative work in small groups;

- require her learners to keep written records of their learning- plans of lessons and projects, lists of useful vocabulary, whatever texts they themselves produce;

- engage her learners in regular evaluation of their progress as individual learners and as a class in the target language. (ibid)

This shows that a teacher is not free in an autonomous class rather he or she has a lot of responsibilities. 
Little (1995) argues that learner autonomy does not mean the lack of any responsibility for the teacher. Teachers, who are taking learner autonomy too literally, according to him, tend to "tell their learners that it is now up to them to be responsible for their learning [...] and withdrawing a corner of the classroom in order to manage the resources that will magically facilitate the 30 or more individual learning processes. When nothing happens, teachers usually conclude that learner autonomy does not work" (p. 178). This highlights the misconception of teachers about their role in the class where the learners are supposed to work autonomously. He further writes "in the promotion of learner autonomy teacher's task is to bring learners to the point where they accept the equal responsibility" (ibid). Teachers cannot promote learner autonomy if they are unaware of it. Therefore to promote learner autonomy according to Little, "We must provide the trainee teachers with skills to develop autonomy in the learners who will be given into their charge but we must also give them the first hand experience of learner autonomy in their training” (p. 179). This practical portion i.e. 'giving firsthand experience' is lacking in our teacher education or training system. Due to this there exists a wide gap between theory and practice. In this regard teacher education or training has been like teaching swimming out of water. Talking about the importance of learner autonomy and promoting learner autonomy are two different things. So teacher education or training should provide them with such learning experience. We should practice what we preach.

Underscoring the role of the teacher in learner autonomy, Lacey (2007) mentions:

The introduction of autonomy leads to very definite changes in teacher/learner roles. The most important change is that the focus is moved from teaching to learning [...]. It is no longer the teacher who has all responsibility for evaluation of unsatisfactory work [...]. In the autonomous class teacher and learners are on the same side, exploring the FL world together. (p. 8)

From the above discussion we can come to the conclusion that learner autonomy does not free the teachers from their responsibility rather it brings change in their roles from authority figure to facilitator, counselor, and prompter. It is the responsibility of teachers to create conditions for learners where they can work on their own. No doubt their works need to be monitored. Teachers need to encourage the students to reflect on their progress and to self-evaluate their work. They also need teacher's feedback; they need teacher's support and scaffolding. Therefore learner autonomy demands the teacher to be more responsible, more planned, and more innovative than he or she is in a traditional class.

\section{Learner autonomy and curriculum}

Curricula are concerned with making general statements about language learning, learning purpose and experience, evaluation and role and relationship of learners and teachers. The language courses which aim to promote learner autonomy should incorporate means of transferring responsibility for aspects of the language learning process (setting goals, selecting learning strategies, and evaluating progress) from the teachers to the learners. According to Cotterall (2000) the curriculum which tends to promote learner autonomy should follow the following principles:

- The course reflects learners' goal in its language, tasks, and strategies;

- Course tasks are explicitly linked to simplified model of the language learning process;

- Course either replicates the real world communicative tasks or provides rehearsal for such tasks;

- The course incorporates discussion and practice with strategies known to facilitate task performance;

- The course promotes reflection on learning (learners being aware of their own learning).

- It will be easier to promote learner autonomy if above principles are considered in designing a language curriculum. (pp. 111-112)

\section{Activities for promoting learner autonomy}

Different activities that provide learners with the opportunity to work independently can be used to promote learner autonomy. Harmer (2008) 
presents a range of activities for training learners to be autonomous, some of which I elaborate upon below.

\section{Thinking about learning}

Learners are provided with the list of 'can do' statements in terms of which they think about their learning. Some examples of 'can do' statements are given below:

- I can use 'can' to express ability.

- I can use 'present perfect tense' to describe experience;

- I can use 'used to' describe past habits, etc.

- Students can also be asked to complete the statements like the following about their learning during the last week:

- The things that I enjoyed most in last week lesson was/were....

- The things that I learnt last week that I did not know before was/were....

- The thing that I could not understand despite my efforts was/were.....

These activities help the learners to reflect on their own learning. Reflection makes their learning long lasting since they are likely to memorize the things they have learned.

Teaching learners to take notes also helps them to be independent learners. Rather than providing the learners with the notes teachers should provide them with various ways of taking notes (spider gram, point by point, spaghetti, etc.). Once they are familiar with different ways of taking notes they can use these skills independently while reading or attending a lecture.

\section{Taking over}

Gradually, learners can take over the responsibility for their own learning. Harmer suggests various activities for this (ibid). Such activities include asking students to use a dictionary which helps them to learn meaning of new words independently, and asking learners to develop their own questionnaire for a survey they want to carry out. Such activities provide learners with a sense of achievement as well as they boost their confidence.

\section{Learning journals}

Learning journals help learners to be autonomous. They also develop learners' writing skills, help express their feelings, help the teacher to better understand their learners, provide an opportunity for learners to think both about what they are learning and how they are learning. They enhance their memory of the things they have learned. Learners might be asked to describe their reaction to a lesson or can be asked to write about anything of their interest. Teachers need to provide feedback on students' writings. Along with providing autonomy journal writing promotes provides them with writing practice as well.

\section{Forcing agency}

Some learners do not just want to take responsibility for their own learning. They feel secure when teachers provide them with the solution to their all problems. Activities like the story circle writing and jigsaw reading activity make learning more structured for students and help them students to contribute something somewhat independently.

\section{The self-access centers (SAC)}

Self-access centers are the centers where learners can choose reading materials according to their own interests. They can visit such centers on regular basis or in their own spare time.

\section{Conclusion: Autonomy in the context of Nepal}

Since learner autonomy promotes lifelong learning, the broader aim of education, we should promote learner autonomy. Learner autonomy works in any culture, though the so-called individualistic cultures may be more supportive to this. We should start from the perspective that all the learners have the power and right to learn autonomously. What should be borne in mind is that successful learners tend to be autonomous. It should also be remembered that total autonomy is neither possible nor desirable, for no one is totally free from the external limitations and restrictions. Teachers always are in constraints. To provide autonomy to the learners teachers should themselves be provided with a certain level of autonomy in the selection of methodology, content, 
tasks, and so on. At the same time teachers should be provided with the opportunity for the firsthand experience of the autonomy in their own training and professional development.

Learner autonomy and curriculum are closely related. As we mentioned earlier, learners should be provided with the opportunity to determine their own goals. This seems to be applicable in most of the formal language learning contexts (schools, colleges and universities) of Nepal, where the learners learn English since it is compulsorily prescribed in the curriculum. However, if the learners choose to study English optionally, they should be provided with the opportunity to set their own goals. Nevertheless, even in the contexts of compulsory English, the need the analysis of the learners before designing the curriculum as well study of the market which consumes the manpower of language education help to set the goals that are in favor of the learners. But other principles mentioned by Cotterall (2000) should be followed in the curriculum.

Learner autonomy does not free teachers from their responsibility. They should be more responsible to promote autonomy in learners. Since teacher autonomy and learner autonomy are closely related, the teacher should also be provided with the opportunity to practice autonomy within the given direction. Teacher education or training should provide teachers with the opportunity to have firsthand experience of autonomy. A teacher who practices autonomy in his/her professional development can better promote learner autonomy. Obviously, learner autonomy can and should both be promoted in English language teaching in Nepal.

\section{References}

Benson, P. (2008). Teachers' and learners perspective on autonomy. In H. R. Terry Lamb, Learner and teacher autonomy:Concepts realities and responses (pp. 4-15). Amsterdam: John Benjamins B.V.

Cotterall, S. (2000). Promoting learner autonomy through the curriculum: Principle for designing language cources. ELT Journal, 52 (2), 109-117.

Crookall, J. H. (1995). Breaking with Chinese cultural traditions:Learner autonomy in English language teaching. System, 20 (2), 235-243.

Dam, L. (2007). Teacher education for learner autonomy. Independence, 42, 1-2.

Harmer, J. (2008). The practice of English language teaching. England: Pearson Longman.

Holliday, A. (2007). Autonomy and cultural Chauvinism. Independence, 42, 20-22.

Holec, H. (1981). Autonomy and foreign language learning. Oxford: Pergamon

Lacey, F. (2007). Autonomy, never, never, never! Independence, 42, 4-8.

Little, D. (1995). Learning as dialogue: The dependence of teacher autonomy on learner autonomy. System 23 (2), 175-181.

Palfreyman, D. (2003). Introduction: Culture and language autonomy. In D. P. Smith, Learner autonomy across cultures: language education perspectives (pp. 1-22). Hampshire: Palgrave Macmilan.

Rodgers, J. C. (2002). Approaches and methods in language teaching. Cambridge: Cambridge University Press.

Schmenk, B. (2006). CALL, self-accessand learner autonomy: A linear proces from heteronomy to autonomy? In A. W. Theo harden, The concept of progression in the teaching and learning of foreign languages (pp. 75-85). Hochfeldstrasse: Peter Lang AG, European Academic Publishers.

Smith, R. (2008). Learner autonomy. ELT Journal, 62(4), 395-397.

Stevens, V. (2007). The multiliterate autonomous learner: Teacher attitudes and the inculcation of strategies for lifelong learning. Independence. 42 , 27-29.

Vieira, F. (2007). Teacher autonomy: Why should we care. Independence, 42, 20-28. 